\title{
Tissue Sodium Content and Arterial Hypertension in Obese Adolescents
}

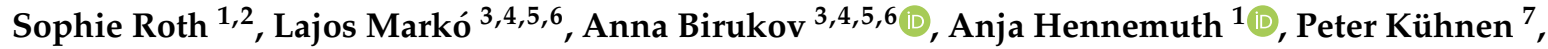 \\ Alexander Jones ${ }^{8}$, Niky Ghorbani ${ }^{1}$, Peter Linz ${ }^{9}{ }^{\mathbb{D}}$, Dominik N Müller ${ }^{3,4,5,6}$, Susanna Wiegand ${ }^{7}$, \\ Felix Berger ${ }^{2,3}$, Titus Kuehne ${ }^{1,2,3}$ and Marcus Kelm ${ }^{1,2, *(1)}$ \\ 1 Institute for Computational and Imaging Science in Cardiovascular Medicine, Charité-Universitätsmedizin \\ 13353 Berlin, Germany; sophie.roth@charite.de (S.R.); anja.hennemuth@charite.de (A.H.); \\ niky.ghorbani@charite.de (N.G.); titus.kuehne@dhzb.de (T.K.) \\ 2 Deutsches Herzzentrum Berlin, Department of Congenital Heart Disease, 13353 Berlin, Germany; \\ berger@dhzb.de \\ 3 DZHK (German Centre for Cardiovascular Research), partner site Berlin, 10785 Berlin, Germany; \\ lajosmarko@yahoo.com (L.M.); anna.birukov@charite.de (A.B.); dominik.mueller@mdc-berlin.de (D.N.M.) \\ 4 Max Delbruck Center for Molecular Medicine, 13092 Berlin, Germany \\ 5 Berlin Institute of Health (BIH), 10178 Berlin, Germany \\ 6 Experimental and Clinical Research Center, a joint cooperation between the Charite Medical Faculty and the \\ Max Delbruck Center for Molecular Medicine, 13125 Berlin, Germany \\ 7 Department of Paediatrics, Charité-Universitätsmedizin Berlin, 13353 Berlin, Germany; \\ peter.kuehnen@charite.de (P.K.); susanna.wiegand@charite.de (S.W.) \\ 8 Department of Paediatrics, University of Oxford, Oxford OX3 9DU, UK; \\ alexander.jones@paediatrics.ox.ac.uk \\ 9 Institute of Radiology, Friedrich-Alexander-University Erlangen-Nürnberg, 91054 Erlangen, Germany; \\ Peter.Linz@uk-erlangen.de \\ * Correspondence: mkelm@dhzb.de; Tel.: +49-(0)30-4593-2864; Fax: +49-(0)30-4505-76983
}

Received: 25 September 2019; Accepted: 15 November 2019; Published: 21 November 2019

\begin{abstract}
Early-onset obesity is known to culminate in type 2 diabetes, arterial hypertension and subsequent cardiovascular disease. The role of sodium $\left(\mathrm{Na}^{+}\right)$homeostasis in this process is incompletely understood, yet correlations between $\mathrm{Na}^{+}$accumulation and hypertension have been observed in adults. We aimed to investigate these associations in adolescents. A cohort of 32 adolescents (13-17 years), comprising 20 obese patients, of whom 11 were hypertensive, as well as 12 age-matched controls, underwent ${ }^{23} \mathrm{Na}$-MRI of the left lower leg with a standard clinical 3T scanner. Median triceps surae muscle $\mathrm{Na}^{+}$content in hypertensive obese $(11.95 \mathrm{mmol} / \mathrm{L}$ [interquartile range 11.62-13.66]) was significantly lower than in normotensive obese $(13.63 \mathrm{mmol} / \mathrm{L}$ [12.97-17.64]; $p=0.043)$ or controls $(15.37 \mathrm{mmol} / \mathrm{L}$ [14.12-16.08]; $p=0.012)$. No significant differences were found between normotensive obese and controls. Skin $\mathrm{Na}^{+}$content in hypertensive obese (13.33 mmol/L [11.53-14.22] did not differ to normotensive obese (14.12 mmol/L [13.15-15.83]) or controls (11.48 mmol/L [10.48-12.80]), whereas normotensive obese had higher values compared to controls $(p=0.004)$. Arterial hypertension in obese adolescents is associated with low muscle $\mathrm{Na}^{+}$ content. These findings suggest an early dysregulation of $\mathrm{Na}^{+}$homeostasis in cardiometabolic disease. Further research is needed to determine whether this association is causal and how it evolves in the transition to adulthood.
\end{abstract}

Keywords: obesity; sodium; hypertension; adolescents; MRI; MR-spectroscopy 


\section{Introduction}

Since the 1980s, the prevalence of obesity in many countries has doubled, affecting an estimated 603.7 million adults and 107.7 million children [1]. Globally, four million deaths per year have been attributed to increased body mass index (BMI), often due to associated cardiovascular disease (CVD) [1]. It is assumed that the course for the development of CVD is already set in childhood, but the exact mechanisms have remained unknown [1]. Amongst others, there are indications for chronic over-activity of the sympathetic nervous system and the renin-angiotensin-aldosterone system (RAAS) [2], as well as obesity-driven low-grade systemic inflammation-promoting type 2 diabetes [3].

Nutrition is known to play an important role in the pathogenesis of obesity, and mineral sodium $\left(\mathrm{Na}^{+}\right)$has been discussed as an essential risk factor for CVD. Many factors may mediate the ability of high salt intake to increase blood pressure, however, their relative contributions to the pathogenesis of salt-induced hypertension are controversial [4,5]. Although several studies report deleterious effects, including a rise in blood pressure and the emergence of chronic kidney disease, some other studies have found more neutral effects [4]. Nevertheless, the rate of deaths from cardiovascular causes has been attributed to sodium consumption, and was found to be lower in regions and cultures with reduced salt intake [5]. In overweight adults, sodium-induced increases in circulating volume and hypertension have been described, which can elevate mortality by promoting left ventricular hypertrophy, altering vascular resistance and ultimately leading to heart failure [6].

Intake and accrual of $\mathrm{Na}^{+}$over the life course may, therefore, be an important determinant of $\mathrm{CVD}$ risk. Measurement of $\mathrm{Na}^{+}$status is routinely done by analysis of spot or $24 \mathrm{~h}$ urines. However, doubts have been raised about the suitability of $24 \mathrm{~h}$ urinary $\mathrm{Na}^{+}$excretion for estimating exact salt intake [7]. Whether urinary $\mathrm{Na}^{+}$excretion is at all reflecting tissue $\mathrm{Na}^{+}$content is currently unknown.

In recent studies, ${ }^{23} \mathrm{Na}$-magnetic resonance imaging (MRI) has been introduced as a reliable, non-invasive method to quantify $\mathrm{Na}^{+}$tissue content [8-13] that overcomes this limitation. It has been suggested that tissue $\mathrm{Na}^{+}$accumulation with ageing could be implicated in the pathogenesis of refractory hypertension in adults [9]. However, these studies were of adult patients with advanced disease, where the independent effects of ageing, as well as hypertension and diet-related obesity, were difficult to separate. Only little is known about $\mathrm{Na}^{+}$storage in children and adolescents. However, studies in younger populations would have the advantage of excluding the effects of advanced ageing or long-established disease. To overcome this knowledge gap, the study investigates the associations between $\mathrm{Na}^{+}$storage, hypertension and obesity in adolescent patients.

\section{Materials and Methods}

In this cross-sectional study twenty, previously untreated obese (aged 13-17 [median 14] years) and twelve normal-weight "control" (aged 13-16 [median 15] years) adolescents were studied. Obese and control subjects were matched for sex and age. Obese patients were recruited prospectively from the social-paediatric centre (Charité-Universitätsmedizin Berlin) between 2014 and 2017, and they were further divided into two sub-groups, according to their blood pressure status. They were defined as obese if their body mass index (BMI) exceeded the 97th Kromeyer-Hauschild percentile according to sex and age [14]. Controls were patients undergoing routine clinical diagnostic MRI for non-cardiac and non-endocrinologic reasons that volunteered to have our ${ }^{23} \mathrm{Na}-\mathrm{MRI}$ protocol added. The primary outcome was the absolute muscle sodium content; the secondary outcome was skin sodium content. Subjects with implanted devices not compatible with MRI and those with claustrophobia were excluded. Written informed consent from participants or their legal guardians was obtained before enrolment. The study was approved by the institutional ethics review board of the Charité-Universitaetsmedizin Berlin (approval reference number EA2/036/14) and conducted according to the principles of the Declaration of Helsinki.

Additionally to known blood pressure status, at the time of MRI, the subjects were comfortably seated with back support for at least five minutes while arterial blood pressure was measured on the right upper arm using an oscillometric Dinamap pro-100 device (Critikon, Milwaukee, WI, USA). 
Cuff size was chosen appropriately to arm circumference. As there is still no single value threshold available in obese and overweight children (BMI $>85$ th percentile) and even adult guideline values vary between ACC and ESC guidelines [14-16], in this study, hypertension was defined if systolic and/or diastolic values exceeded age-, gender- and height-specific (95th) [16] reference percentiles.

Anthropometric data were acquired using standardised clinical protocols and participants completed a questionnaire about salt intake, answering on a scale of 1-10 according to their agreement with the question asked. An oral glucose-tolerance test (OGTT) was performed and $\mathrm{HbA1c}$, fasten insulin and glucose were measured. Homeostatic model assessment (HOMA) indices above 2.0 were considered hyperinsulinism.

All subjects rested for at least $15 \mathrm{~min}$ before their left calf was scanned at its widest circumference. Imaging was performed on a Philips Ingenia 3.0 Tesla MR scanner (Ingenia R 5.4, Philips Healthcare, Best, The Netherlands) with a ${ }^{23} \mathrm{Na}$ send/receive knee-coil (Rapid Biomedical, Rimpar, Germany), following previously validated methods, using a 2D-spoiled gradient echo sequence (total acquisition time, $\mathrm{TA}=20.5 \mathrm{~min}$; echo time, $\mathrm{TE}=2.138 \mathrm{~ms}$; repetition time, $\mathrm{TR}=100 \mathrm{~ms}$; flip angle, $\mathrm{FA}=90^{\circ}$; 196 averages, resolution: $3 \times 3 \times 30 \mathrm{~mm}^{3}$ ) [9,10]. Four calibration phantoms containing aqueous solutions of $10,20,30$, and $40 \mathrm{mmol} / \mathrm{L} \mathrm{NaCl}$ were scanned as reference standards, together with the subject's calf. Simultaneously, tissue water content was measured by ${ }^{1} \mathrm{H}-\mathrm{MRI}$, using a fat-saturated inversion-prepared SE sequence (inversion time, $\mathrm{TI}=210 \mathrm{~ms}$; TA $=6.27 \mathrm{~min} ; \mathrm{TE}=12 \mathrm{~ms}$; TR $=3000 \mathrm{~ms}$; FA $=90^{\circ} ; 1$ average, resolution: $\left.1.5 \times 1.5 \times 5 \mathrm{~mm}^{3}\right)$, as implemented by other investigators [11].

Using ImageJ (NIH, version 1.50i) and the anatomical image (T1-weighted spoiled gradient echo sequence) as guidance, regions of interest (ROI) were drawn as centrally as possible whilst excluding prominent vascular structures, which are rich in $\mathrm{Na}^{+}$. Relevant ROIs included the total leg, triceps surae muscle, as the largest muscle of the calf (with medial and lateral gastrocnemius and soleus; referred in the text as "muscle"), skin, tibial bone and subcutaneous fat. Muscle ROIs and subcutaneous ROIs were marked on the T1-weighted sequence, while skin ROI, total leg ROI and phantom ROIs were drawn on the $\mathrm{Na}^{+}$image, as already described by other authors [11]. ROI areas were assessed through each ROI's voxel count and measured in arbitrary units (AU).

The signal intensity of each ROI was measured and linear trend analysis was used to translate this intensity to a $\mathrm{NaCl}$ concentration, according to the calibration phantoms' predefined contents of 10,20 , 30, and $40 \mathrm{mmol} / \mathrm{L}$ [17]. A calibration standard for tissue water was based on the water content of the $10 \mathrm{mmol} / \mathrm{L} \mathrm{NaCl}$ tube. Previous studies have suggested ${ }^{1} \mathrm{H}-\mathrm{MRI}$ as a means to non-invasively assess tissue water content changes, based on a linear relationship between ${ }^{1} \mathrm{H}-\mathrm{MRI}$ measurements and actual water content [9]. Thus, the combination of water and $\mathrm{Na}^{+}$measurements allows the differentiation of a water-dependent $\mathrm{Na}^{+}$storage (e.g., oedema) from water-independent $\mathrm{Na}^{+}$storage (e.g., bound to glycosaminoglycans) [18].

Since fat tissue is rather low in $\mathrm{Na}^{+}$content, we assessed whether decreased $\mathrm{Na}^{+}$content in muscle might be due to increased muscle fat accumulation. Muscle fat content was assessed by the ratio of fat-voxels and the total number of voxels within the muscle. As described by Kopp et al., ${ }^{1} \mathrm{H}$-T1-weighted tissue signal intensities greater than $30 \%$ above the intensity level of the phantom tubes were defined "fat-voxels" [19]. The ratio of fat-voxels and the total number of voxels within the muscle was used to assess fatty muscle degeneration.

Data are expressed as median and interquartile range (Q1-Q3) unless otherwise stated. Data were tested for normality using the Shapiro-Wilk and Shapiro-Francia tests. Data were analysed for stochastic dominance among the three groups by applying a non-parametric Kruskal-Wallis test, followed by a Bonferroni-corrected Dunn's test as a nonparametric, pairwise, multiple comparison procedure. Pearson's chi-square test was used with Fisher's exact test for comparison of categorical variables. To plot the combined effects of BMI and hypertension on $\mathrm{Na}^{+}$content in muscle, predictive margins were calculated and plotted. Correlations were assessed by non-parametric multivariate regression analysis. Multifactorial effects (and their $95 \%$ confidence interval, CI) were assessed using robust regression. Significance level was set at $p=0.05$ and $95 \%$ confidence intervals were 
calculated. Inter-observer variability was evaluated for $\mathrm{Na}^{+}$measurements of 25 different subjects using a Bland-Altman plot. Stata (Version 15.1, StataCorp, College Station, Texas, USA) was used for statistical analysis.

\section{Results}

$\mathrm{Na}^{+}$content and tissue water content was analysed in a total of 32 subjects, of which 11 were hypertensive obese patients, nine normotensive obese patients and 12 normal-weight controls. The characteristics of these three groups are shown in Table 1. Age and sex did not significantly differ between groups, and BMI did not differ between both obesity groups (Figure 1a). Heart rate, systolic and diastolic blood pressure did not differ between normotensive obese and controls, but did between those two groups and hypertensive obese (Figure $1 b-d$, respectively). Only one patient had isolated diastolic blood pressure values exceeding the 95th percentile. All remaining hypertensive patients had systolic hypertension.
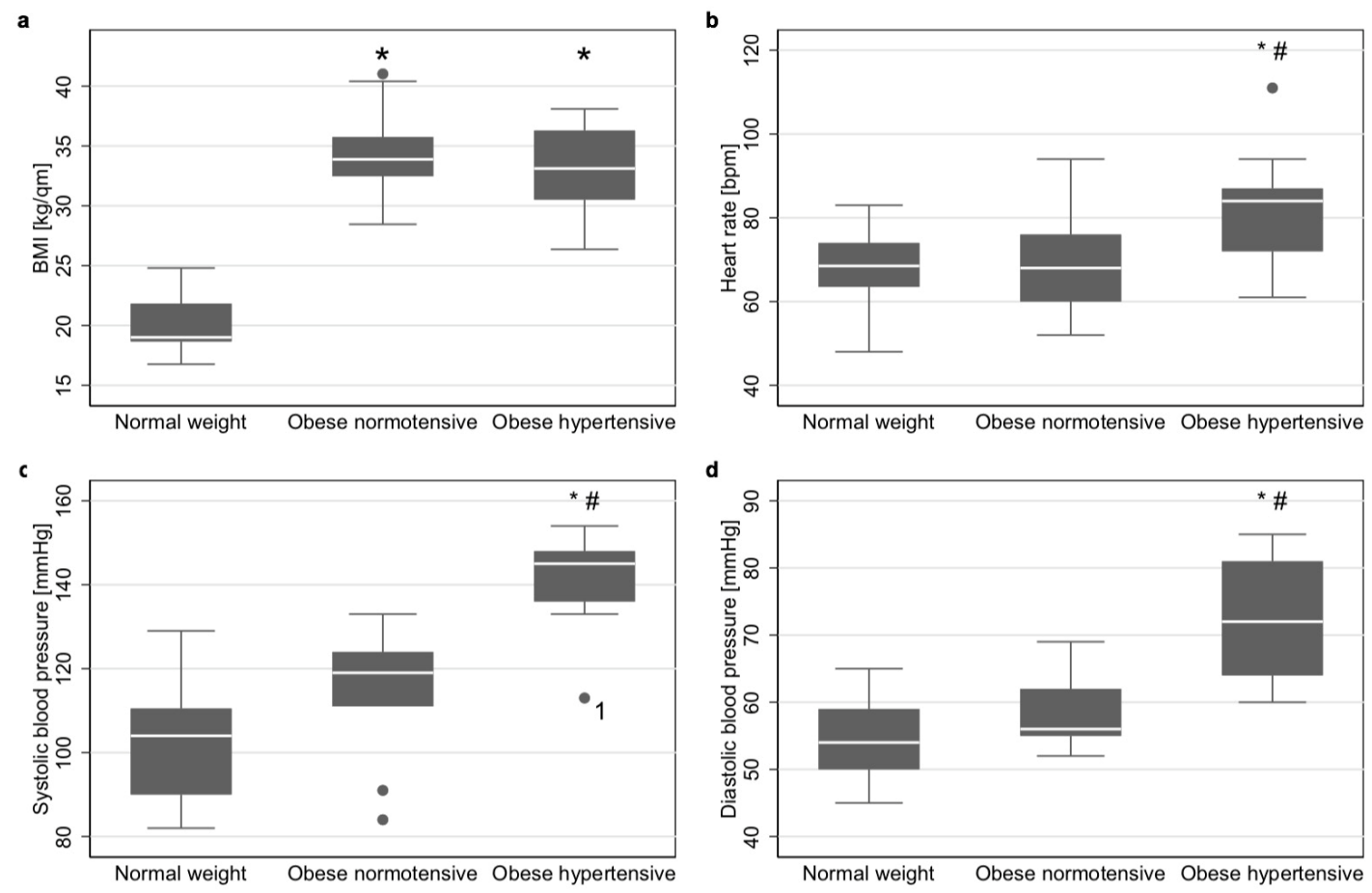

Figure 1. Group characteristics. (a) Boxplots of body-mass index (BMI) of controls, normotensive obese and hypertensive obese. (b) Boxplots of heart rate of controls, normotensive obese and hypertensive obese. (c) Boxplots of systolic blood pressure of controls, normotensive obese and hypertensive obese. (d) Boxplots of diastolic blood pressure of controls, normotensive obese and hypertensive obese. Tests were performed using a Kruskal-Wallis Test $(\mathrm{N}=32)$ with inter-group p-values according to Bonferroni corrected Dunn's test. * $p$-value $<0.05$ compared to controls \# $p$-value $<0.05$ compared to normotensive obese. ${ }^{1}$ diastolic hypertension (above the 95 th percentile). 
Table 1. Baseline characteristics. Median (interquartile range), unless stated otherwise.

\begin{tabular}{|c|c|c|c|c|c|c|c|}
\hline Subjects & Controls $(n=12)$ & $\begin{array}{l}\text { Normoten-Sive } \\
\text { Obese }(\mathrm{n}=9)\end{array}$ & $\begin{array}{l}\text { Hyperten-Sive } \\
\text { Obese }(n=11)\end{array}$ & $\begin{array}{c}p \text { Value } \\
\text { Normotensive Obese } \\
\text { vs. Controls }\end{array}$ & $\begin{array}{l}p \text { Value Hypertensive } \\
\text { Obese vs. Controls }\end{array}$ & $\begin{array}{c}p \text { Value Hypertensive } \\
\text { Obese vs. Normotensive } \\
\text { Obese }\end{array}$ & $\begin{array}{l}p \text { Value } \\
\text { Overall }\end{array}$ \\
\hline Age [years] & $15(14-16)$ & $15(14-16)$ & $14(13-14)$ & 1.000 & 0.088 & 0.060 & 0.072 \\
\hline Male Gender (n) & $4(33 \%)$ & $4(44 \%)$ & $5(45 \%)$ & & & & 0.808 \\
\hline $\begin{array}{l}\text { Cross-Sectional Total Leg } \\
\text { Area }\left(\mathrm{mm}^{2}\right)\end{array}$ & $3830(3536-4387)$ & $6862(5917-7244)$ & $5912(5217-6369)$ & $<0.001$ & 0.0007 & 0.533 & $<0.001$ \\
\hline Tibial Bone Area $\left(\mathrm{mm}^{2}\right)$ & $229(208-244)$ & $311(245-322)$ & $284(225-317)$ & 0.011 & 0.117 & 0.478 & 0.022 \\
\hline Total muscle area $\left(\mathrm{mm}^{2}\right)$ & $2265(1989-2482)$ & $3196(2780-3565)$ & $2960(2750-3377)$ & 0.002 & 0.003 & 1.000 & 0.001 \\
\hline Subcutaneous Fat Area $\left(\mathrm{mm}^{2}\right)$ & $1084(950-1363)$ & $2526(2078-3787)$ & $2128(1824-2939)$ & $<0.001$ & 0.001 & 0.758 & $<0.001$ \\
\hline \multicolumn{8}{|l|}{ Questionnaire } \\
\hline $\begin{array}{l}\text { "How much do you like } \\
\text { salty food?" }\end{array}$ & $7(5.5-7.5)$ & $6(5-8)$ & $5(3-8)$ & 1.000 & 0.400 & 0.352 & 0.419 \\
\hline $\begin{array}{l}\text { "How often do you add more } \\
\text { salt to your food" }\end{array}$ & $3.5(2-6.5)$ & $3(1-5)$ & $2(1-3)$ & 0.497 & 0.059 & 0.504 & 0.129 \\
\hline $\begin{array}{l}\text { "How much do you like salty } \\
\text { snacks such as crisps?" }\end{array}$ & $8(5.5-8)$ & $5(4-7)$ & $7(4-9)$ & 0.242 & 0.916 & 0.552 & 0.379 \\
\hline $\begin{array}{l}\text { "How often do you eat in fast } \\
\text { food restaurants?" }\end{array}$ & $4(2.5-4.5)$ & $4(3-5)$ & $3(2-4)$ & 1.000 & 0.088 & 0.126 & 0.124 \\
\hline $\begin{array}{l}\text { “How much money do you } \\
\text { usually spend there?" }(€)\end{array}$ & $5(2.8-8)$ & $9(5-10)$ & $5(4-9.5)$ & 0.197 & 1.000 & 0.161 & 0.218 \\
\hline $\begin{array}{c}\text { "How often do you drink } \\
\text { beverages without additional } \\
\text { flavour?" }\end{array}$ & 7 (5-9.5) & $10(9-10)$ & $10(8-10)$ & 0.166 & 0.058 & 1.000 & 0.122 \\
\hline $\begin{array}{l}\text { "How much do you drink } \\
\text { daily?" (L) }\end{array}$ & $1.5(1.1-2)$ & $1.5(1-2.5)$ & $2(1-2.3)$ & 0.601 & 0.524 & 1.000 & 0.587 \\
\hline
\end{tabular}

Questionnaire on a scale from 1-10 (1 = I strongly agree; 10 = I strongly disagree) unless stated otherwise. 


\subsection{Tissue $\mathrm{Na}^{+}$, Water and Fat Content}

We found significant differences in tibial bone $\mathrm{Na}^{+}$content, subcutaneous fat $\mathrm{Na}^{+}$content and water content of muscle, skin, tibial bone and subcutaneous fat in none of the groups (Supplementary Figure S1).

Muscle $\mathrm{Na}^{+}$content did not differ $(p=1.00)$ between controls $(15.37 \mathrm{mmol} / \mathrm{L}$ [interquartile range 14.12-16.08]) and normotensive obese (13.63 mmol/L [12.97-17.64]), but was significantly lower than both of these groups ( $p=0.012$ and $p=0.043$, respectively) in hypertensive obese $(11.95 \mathrm{mmol} / \mathrm{L}$ [11.62-13.66]) (Figure 2a). The Bland-Altman plot showed only low inter-observer variability in muscle $\mathrm{Na}^{+}$content, due to variations in data processing (Supplementary Figure S2).

a
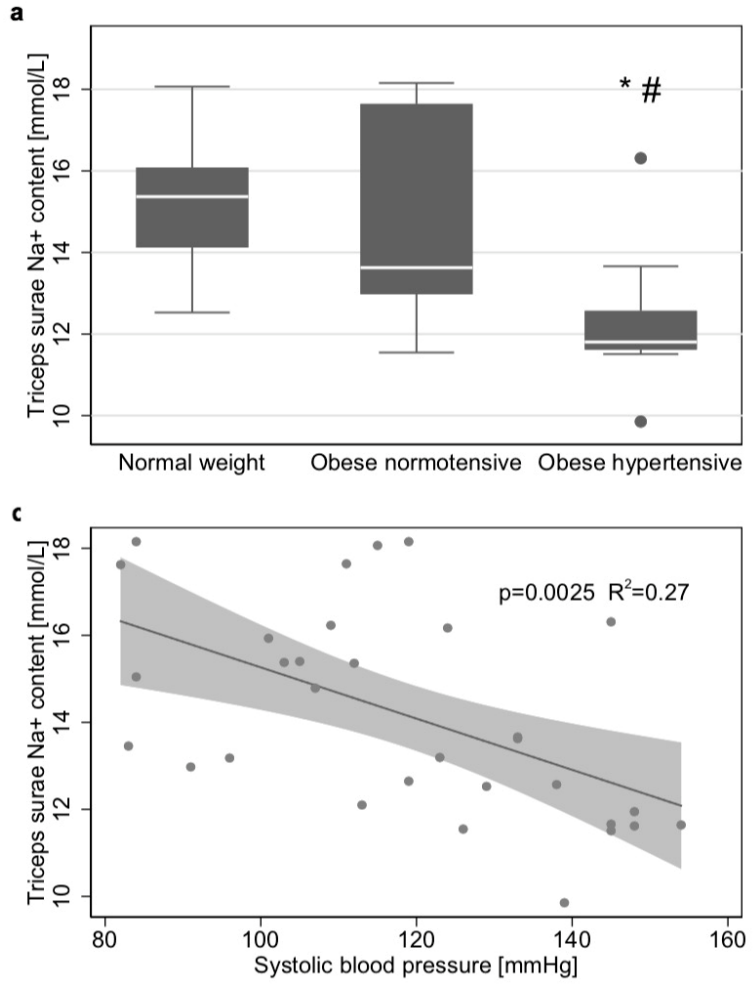

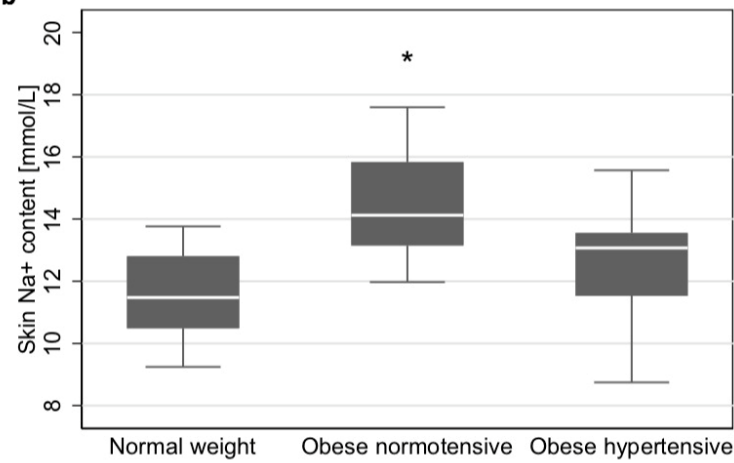

d

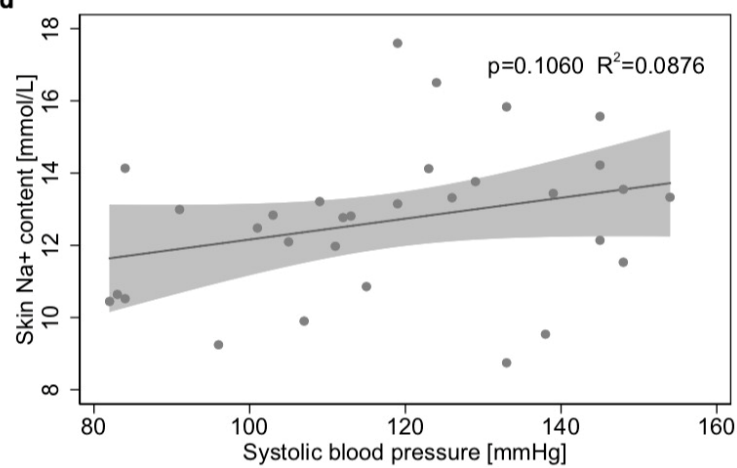

Figure 2. $\mathrm{Na}^{+}$content in different tissues. (a) Boxplots of triceps surae muscle $\mathrm{Na}^{+}$of controls, normotensive obese and hypertensive obese. (b) Boxplots of skin $\mathrm{Na}^{+}$content of controls, normotensive obese and hypertensive obese. Tests were performed using a Kruskal-Wallis Test $(\mathrm{N}=32)$ with inter-group $p$-values according to Bonferroni corrected Dunn's test. * $p$-value $<0.05$ compared to controls \# $p$-value $<0.05$ compared to normotensive obese. ${ }^{1}$ diastolic hypertension (above the 95 th percentile). (c) The scatter plot and the linear regression model show an inverse correlation between triceps surae $\mathrm{Na}^{+}$content and systolic blood pressure $\left(p=0.0025, \mathrm{R}^{2}=0.27, \mathrm{~N}=32\right)$. (d) Scatter plot and the linear regression model, showing no significant correlation between skin $\mathrm{Na}^{+}$content and systolic blood pressure $\left(\mathrm{p}=0.1060 \mathrm{R}^{2}=0.09\right)$.

In contrast, skin $\mathrm{Na}^{+}$content in normotensive obese (14.12 mmol/L [13.15-15.83]) was significantly higher $(p=0.004)$ than in controls $(11.48 \mathrm{mmol} / \mathrm{L}$ [10.48-12.80]), while it tended to be higher in hypertensive obese (13.33 mmol/L [11.53-14.22]; $p=0.144)$. There was no difference between obese adolescents with or without hypertension $(p=0.237)$ (Figure $2 b)$.

Cross-sectional total $\mathrm{Na}^{+}$content of all compartments in hypertensive obese was $12.01 \mathrm{mmol} / \mathrm{L}$ [11.41-12.89] and was significantly lower than in normotensive obese $(\mathrm{p}=0.045)$ and controls $(p=0.005)$. Total $\mathrm{Na}^{+}$content did not significantly differ between controls (15.15 mmol/L [12.70-15.69]) and normotensive obese (13.02 mmol/L [12.39-14.98]; $p=0.866)$. 
The proportion of fat tissue within the muscle did not vary between all three groups. No significant correlation was found $\left(p=0.149, \mathrm{R}^{2}=0.037\right.$ ) between the amount (area) of fat tissue and muscle sodium content (Table 1).

\section{2. $\mathrm{Na}^{+}$Content and Arterial Hypertension}

As recent studies have reported correlations between $\mathrm{Na}^{+}$accumulation and hypertension in adults [9], we further investigated these aspects in an adolescent cohort: an inverse correlation was found between muscle $\mathrm{Na}^{+}$content and systolic blood pressure $\left(p=0.0025 ; \mathrm{R}^{2}=0.27\right.$; Figure $\left.2 \mathrm{c}\right)$ and cross-sectional total sodium content $\left(p=0.0173, R^{2}=0.12\right)$. These effects were not attributed to BMI. In obese patients, no significant correlations were found between BMI and muscle $\mathrm{Na}^{+}$content and total cross-sectional $\mathrm{Na}^{+}$content. No significant correlation was found between skin $\mathrm{Na}^{+}$content and systolic blood pressure (Figure 2d).

Since a relationship between arterial hypertension and heart rate increase was described in the literature for obesity, heart rates were also compared between groups2. The heart rate in hypertensive obese (84 [72-87]) was significantly higher ( $\mathrm{p}=0.008$ and $\mathrm{p}=0.025$, respectively) than in controls (69 [64-74]) and normotensive obese (68 [60-76]). Between controls and normotensive obese, heart rate did not differ $(p=0.386$, Figure 1b).

A logistic regression model (Figure 3) in obese showed that the probability of hypertension was significantly associated with lower muscle $\mathrm{Na}^{+}$content $(p=0.038)$. The risk for hypertension and its uncertainty is also shown in the figure, and was increased to $>80 \%$ in patients with triceps surae muscle $\mathrm{Na}^{+}$content below $12 \mathrm{mmol} / \mathrm{L}$.

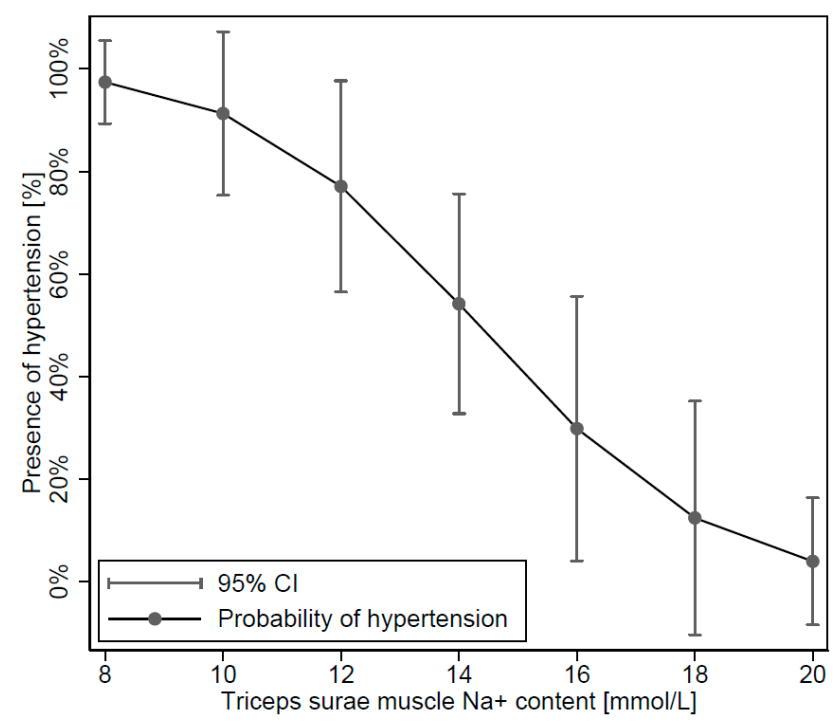

Figure 3. Logistic model showing the probability of hypertension according to muscle $\mathrm{Na}^{+}$content with $95 \%$ confidence intervals $(C I) .(p=0.038 ; \mathrm{N}=32)$.

\subsection{Sex Differences in $\mathrm{Na}^{+}$Content and Arterial Hypertension}

Sex differences were assessed for all storage compartments. No significant sex-specific differences were found for muscle $\mathrm{Na}^{+}$content. Additionally, the associations between arterial hypertension and muscle sodium content, as well as total sodium content, were independent of the patient's sex. Robust linear regression demonstrated associations $\left(p<0.001 ; \mathrm{R}^{2}=0.40\right)$ between skin $\mathrm{Na}^{+}$content and independent variables of (1) female sex (Coef. $-1.3195 \%$ CI -2.52 to $-0.10, p=0.034$ ) and (2) being normotensive obese (Coef. $2.6995 \%$ CI 1.20 to $4.19, p=0.001$ ) but not (3) being hypertensive obese $(p=0.201)$. Tibial bone $\mathrm{Na}^{+}$content was significantly lower in obese females $(4.71 \mathrm{mmol} / \mathrm{L}$ [1.38-6.63]) than in obese males $(7.45 \mathrm{mmol} / \mathrm{L}$ [6.10-9.14]; $p=0.025)$. Robust linear regression showed an association $\left(p=0.023 ; R^{2}=0.25\right)$ between tibial bone $\mathrm{Na}^{+}$content and independent variables of (1) female sex 
(Coef. $-3.20,95 \%$ CI -5.85 to $-0.55, p=0.020)$, but not (2) being hypertensive obese $(p=0.624)$ or (3) normotensive obese $(p=0.389)$. In other compartments, we did not find sex-specific differences in $\mathrm{Na}^{+}$content.

\subsection{Salt Intake, Tissue $\mathrm{Na}^{+}$and Glucose Metabolism}

The responses to the questionnaire items in all groups are shown in Table 1. In all items, no differences were found between groups regarding salt appetite or salty fast food craving.

Hyperinsulinism, reflected by a HOMA index of 2.0 or higher, was found in $87 \%$ of all obese patients. We found a weak correlation between $\mathrm{HbA1c}$ and systolic blood pressure $\left(p=0.088 ; \mathrm{R}^{2}=0.18\right.$ $\mathrm{n}=19$; Figure $4 \mathrm{a}$ ), but a stronger one between $\mathrm{Na}^{+}$content of the whole leg and blood glucose levels after $1 \mathrm{~h}\left(p=0.034 ; \mathrm{R}^{2}=0.63 ; \mathrm{n}=11 ;\right.$ Figure $\left.4 \mathrm{~b}\right)$ and $2 \mathrm{~h}$ of OGTT $\left(\mathrm{p}=0.084 ; \mathrm{R}^{2}=0.56 ; \mathrm{n}=11\right.$; Figure $\left.4 \mathrm{c}\right)$. These effects were not found in other tissue compartments.
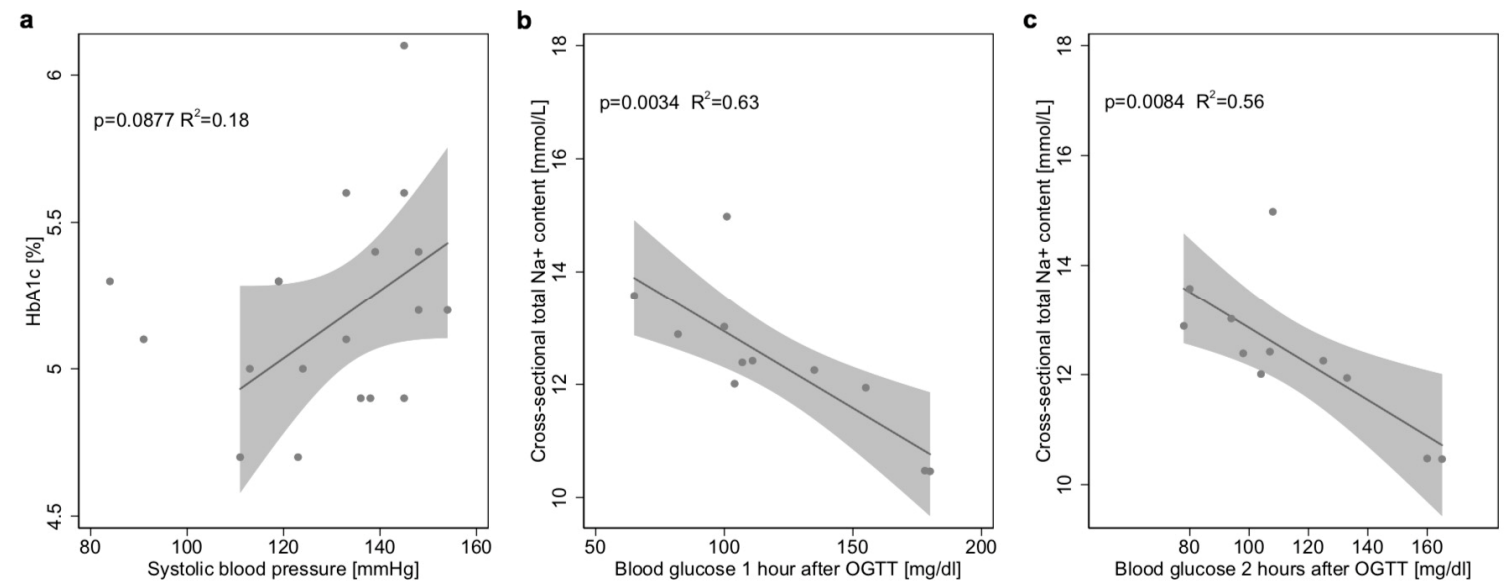

Figure 4. Tissue $\mathrm{Na}^{+}$and glucose metabolism. (a) Linear regression model with $95 \%$ CI combined with scatter plot, showing no significant correlation between $\mathrm{HbA1c}$ and systolic blood pressure ( $n=19$ ). (b) Linear regression model with $95 \%$ CI, combined with scatter plot showing a significant correlation between $\mathrm{Na}^{+}$of the whole leg and blood glucose $1 \mathrm{~h}$ after an oral glucose tolerance test (OGTT, $p=0.0034 \mathrm{R}^{2}=0.63, \mathrm{n}=11$ ). (c) The linear regression model with $95 \% \mathrm{CI}$, combined with scatter plot showing a significant correlation between $\mathrm{Na}^{+}$of the whole leg and blood glucose $2 \mathrm{~h}$ after an OGTT $\left(p=0.0084 \mathrm{R}^{2}=0.56, \mathrm{n}=11\right)$.

\subsection{Power Calculation}

A power calculation using a Satterthwaite's t-test for unequal variances, based on relevant differences in muscle sodium content, and a group A (hypertensive obese) mean of $12.8 \pm 1.877$ and a group B (control) mean of $15.248 \pm 1.657 \mathrm{mmol} / \mathrm{L}$, a total sample size of $\mathrm{N}=23$ for both groups and a level of significance of $5 \%$ (two-sided), resulted in an estimated power of $92 \%$. To estimate statistical power of differences between normotensive and hypertensive obese, a Group A (normotensive obese) mean of $14.9 \pm 2.6190$ and a Group B (control) mean of $15.248 \pm 1.657 \mathrm{mmol} / \mathrm{L}$, a total sample size of $\mathrm{N}=20$ for both groups and a level of significance of $5 \%$ (two-sided) resulted in an estimated power of $57 \%$.

\section{Discussion}

Little progress has been made in preventing the emergence of cardiovascular risk factors, such as obesity and hypertension in their early stages $[1,20]$. The pathophysiological link between these conditions and the role of mineral $\mathrm{Na}^{+}$intake remains incompletely understood, hampering the development of targeted prevention measures. In previous studies, tissue $\mathrm{Na}^{+}$accumulation has been proposed as a factor in the pathogenesis of hypertension, based on findings of raised tissue $\mathrm{Na}^{+}$ in hypertensive adults [9], but its association with blood pressure status in childhood has not been 
studied before. We found that obese adolescents with hypertension had lower triceps surae muscle $\mathrm{Na}^{+}$and lower total cross-sectional $\mathrm{Na}^{+}$content than those without hypertension or normotensive controls. These effects were independent of the patients' BMI. When comparing our results with those of hypertensive adults, one must be aware that these studies, to our knowledge, do not consistently provide information on patients' weight [9]. Future studies should, therefore, further investigate to what extent tissue sodium storage in hypertensive and normotensive adults is linked to mechanisms of ageing and obesity.

\subsection{Tissue $\mathrm{Na}^{+}$Contents in Adults}

${ }^{23} \mathrm{Na}-\mathrm{MRI}$ has been established as a non-invasive method for the quantification of $\mathrm{Na}^{+}$content in different tissues $[9-13,21]$. Although our picture of $\mathrm{Na}^{+}$homeostasis and tissue storage is still fragmented, this novel approach has made it possible to gain a considerable amount of knowledge in recent years. Tissue $\mathrm{Na}^{+}$content was previously found to be elevated, among others, in patients with lipoedema [22], acute heart failure [11] or acute kidney disease [12] and chronic kidney disease [13]. In patients with refractory hypertension, women showed increased skin $\mathrm{Na}^{+}$content compared to controls, whereas men showed higher muscle $\mathrm{Na}^{+}$content compared to controls [9]. Increasing age further intensifies these differences in compartment distribution [17]. Additionally, sex differences have been described in a recent study [17]. In our study, we found higher skin and tibial bone $\mathrm{Na}^{+}$ content in males. Although these findings are in line with previous studies for the skin, the tibial bone has not yet been described as a compartment for sodium storage/depletion in patients with normal renal function, as its overall sodium content is typically much lower than that in the muscle/skin.

\section{2. $\mathrm{Na}^{+}$and Blood Pressure}

The World Health Organization (WHO) recommends less than $2 \mathrm{~g} /$ day $\mathrm{Na}^{+}$in adults, and even lower doses in children [23]. As the actual mean daily intake of $\mathrm{Na}^{+}$is as high as $3.6 \mathrm{~g} /$ day in the US, UK, and Germany, we presume high salt intake also plays an important role in our study cohort [5]. Using questionnaires to semi-quantify the "salt appetite" of our participants, we did not observe any differences between the groups. However, to record the actual salt intake, complex measurements of nutritional composition would be required.

Salt-loading studies with salt-resistant subjects have shown that, during acute or chronic salt-loading, normotensive salt-resistant subjects do not excrete $\mathrm{Na}^{+}$faster, nor do they experience more blood volume expansion. Instead, they substantially retain $\mathrm{Na}^{+}$in a rhythmical manner, which is in line with our concept of relevant tissue $\mathrm{Na}^{+}$buffers [24,25]. Impairment of these buffer mechanisms in our "early disease stage" study could be an important contributor to the onset of arterial hypertension: while, in obese young patients without hypertension, $\mathrm{Na}^{+}$storage in the muscle (the largest previously described buffer compartment) is only slightly reduced, in those with hypertension we observed an accentuated reduction of $\mathrm{Na}^{+}$storage in muscle. In other compartments, such as the skin, tibial bone and subcutaneous fat, $\mathrm{Na}^{+}$did not show significant differences in hypertensive obese, excluding a potential $\mathrm{Na}^{+}$shift to those compartments nearby.

Previous studies observed salt-sensitivity in some individuals, which describes an increase in blood pressure as a response to increases in dietary $\mathrm{Na}^{+}$intake and vice versa $[20,25,26]$. In this context, the RAAS seems to be an important factor: it controls the vascular tone and-through $\mathrm{Na}^{+}$ reabsorption - the intravascular volume homeostasis, as well as the heart rate, through Angiotensin II activation [2,27]. Presuming similar $\mathrm{Na}^{+}$intake in all groups, without a significant shift to other compartments, impaired muscle $\mathrm{Na}^{+}$storage in hypertensive obese can result in elevated $\mathrm{Na}^{+}$excretion through two major mechanisms: 1) altered RAAS suppression [28] and 2) pressure natriuresis as a regulatory response mechanism in salt-sensitive hypertensive subjects [29] through hypertension itself. Elevated heart rates in our cohort of hypertensive obese are in line with an overactivation of the sympathetic nervous system that has been described as an essential factor in the pathogenesis of obesity-induced hypertension in rabbits, dogs and humans [2]. 
In adults with long-term hypertension, recent reports suggest osmotically inactive $\mathrm{Na}^{+}$storage in the skin via negatively charged glycosaminoglycans as binding partners [18]. We found elevated skin $\mathrm{Na}^{+}$content in normotensive obese compared to normal-weight controls. However, these effects were not found in hypertensive obese. Therefore, no such conclusions can be made for skin $\mathrm{Na}^{+}$content in adolescents.

Before $\mathrm{Na}^{+}$transfers from the vascular system to tissue, there are two barriers to overcome: the negatively charged endothelial glycocalyx layer and the endothelial $\mathrm{Na}^{+}$channel $\mathrm{ENaC}$ [30]. Therefore, $\mathrm{Na}^{+}$homeostasis and salt sensitivity in arterial hypertension might be associated not only with a subnormal ability to excrete sodium load, but also with vascular endothelial dysfunction [24,27]. Whereas in patients with different stages of chronic kidney disease, salt restriction can reduce blood pressure [31], no controlled studies have been performed to demonstrate that hypertensive subjects excrete sodium more slowly and retain more of it than normotensive subjects.

One could, therefore, speculate whether regulatory mechanisms in adolescents are different from those observed in older patients. If the muscle, as a main $\mathrm{Na}^{+}$storage compartment, stores less, maintenance of blood sodium homeostasis will depend more on excretion and other storage compartments. This may reflect a compensatory mechanism at an early stage of the disease-preventing tissue $\mathrm{Na}^{+}$overload, and further research will be needed to investigate the hormonal cascades involved, as well as absolute $\mathrm{Na}^{+}$excretion, as plasma $\mathrm{Na}^{+}$needs to maintain stable.

\section{3. $\mathrm{Na}^{+}$Homeostasis and Hyperinsulinism}

Insulin alone has long been thought to cause $\mathrm{Na}^{+}$retention, with enough effects to contribute to arterial hypertension [32,33]. A study by Brands and colleagues showed that such $\mathrm{Na}^{+}$-retaining effects may be limited to uncontrolled Type II diabetes [32]. In 11 maintenance haemodialysis patients, higher muscle sodium content was, in a similar way, associated with insulin resistance [34]. Furthermore, in the soleus muscle of salt-sensitive hypertensive Dahl rats, the RAAS was shown to activate the NF- $\mathrm{kB}$ pro-inflammatory pathway, inducing moderate hyperinsulinemia and insulin resistance [33]. A recent study also demonstrated a positive statistical correlation between $\mathrm{Na}^{+}$intake and insulin resistance in obese children and adolescents [35]. A majority (87.5\%) of our disease cohort not only had hyperinsulinism, but were also showing a trend between $\mathrm{HbA} 1 \mathrm{c}$ and blood pressure, even at this early stage of the disease.

Although the relation between obesity and hyper-caloric diets is known, the association between obesity and $\mathrm{Na}^{+}$still remains unclear, as the quantification of salt intake is measured highly subjectively, through questionnaires or food records, unless investigators have the unusual opportunity of controlling their subjects' nutrition completely, as done by Titze et al. in their space flight simulations [25]. In our study, we used salt questionnaires to assess the habits of salt intake and did not note any elevation of salt consumption or salty fast food craving in hypertensive or normotensive obese compared to our controls.

\section{4. ${ }^{23} \mathrm{Na}-\mathrm{MRI}$}

Due to its non-invasive nature, ${ }^{23} \mathrm{Na}-\mathrm{MRI}$ is increasingly used in clinical research projects, even though it requires the use of specific non-proton coils and yields a certain complexity in image acquisition and post-processing [8-13,21].

Our study was performed at a 3 Tesla clinical scanner with a previously described measurement set-up $[9,10]$. A calibration curve using aqueous reference saline solutions was generated alongside to all scans, and 196 signal averages were applied to improve image homogeneity. We also determined intra- and inter-observer variability that did not show any significant differences between measurements. Compartments were assessed separately, as the total-cross-sectional $\mathrm{Na}^{+}$content (shown for completeness) can be prone to averaging artefacts when different tissue types are combined, and the effects of the largest storage compartments (the muscle) may dominate. 


\subsection{Limitations}

Within this study, we did not perform interventions such as salt loading tests, and, furthermore, assessments of the RAAS and $\mathrm{Na}^{+}$excretion were not part of the study protocol. As indicated by our findings, future prospective and longitudinal studies should further evaluate the impact of such interventions and assess the complex interplay of hormonal axes (including the RAAS), as well as their linkage to the inflammation and glucose/insulin metabolism, as this may be of high relevance in future treatment-planning strategies. Furthermore, and as already stated above, salt intake was not measured quantitatively.

Statistical power to assess differences in muscle sodium content between controls and hypertensive obese was $92 \%$, however, it was $57 \%$ for differences between controls and normotensive obese, due to sample size and the large heterogeneity within normotensive obese. These findings may be of use for future study planning.

\section{Clinical Outlook and Conclusions}

In obese adolescents with hyperinsulinism, arterial hypertension occurs in the presence of low muscle tissue $\mathrm{Na}^{+}$content, independent of the patient's BMI. These findings suggest a different regulation of muscle $\mathrm{Na}^{+}$homeostasis and storage in early-onset obesity for hypertension compared to normotensive patients, adding a new perspective to salt-induced hypertension and salt sensitivity, if main storage compartments store less. The role of $\mathrm{Na}^{+}$storage, salt sensitivity and insulin resistance in the initial stages of arterial hypertension, and the extent of the compensatory mechanisms that can become maladaptive at a later stage of the disease, as well as differences to isolated arterial hypertension in adults, remain to be further investigated in future clinical research.

Supplementary Materials: The following are available online at http:/www.mdpi.com/2077-0383/8/12/2036/s1, Figure S1: $\mathrm{Na}^{+}$and water content in different tissues, Figure S2: Bland-Altman Plot illustrating the inter-observer variability in the post-processing of the ${ }^{23} \mathrm{Na}$ MRI data, Figure S3: Sex-specific tibial bone $\mathrm{Na}^{+}$.

Author Contributions: Conceptualization, T.K., D.N.M. and M.K.; Methodology, P.L., D.N.M., L.M.; Software, A.H.; Formal Analysis S.R., A.H., A.B., N.G., P.K., M.K.; Investigation, M.K., S.R.; Resources, T.K., F.B., S.W., S.K.; Data Curation, S.R.; Writing-Original Draft Preparation, S.R., M.K.; Writing-Review and Editing, T.K., A.J., S.W., S.K., F.B.; Visualization, M.K.; Supervision, T.K., F.B., S.W.; Project Administration, T.K., M.K.; Funding Acquisition, T.K., A.J., M.K. All authors read and approved the final manuscript and agree to be accountable for all aspects of the work.

Funding: This study was partially funded by the European Commission under the FP7-ICT Program (Grant No: 600932, Brussels, Belgium). M.K. receives funding from the Berlin Institute of Health (BIH, Berlin, Germany) within the Digital Clinician Scientist Program (07/2019-07/2022).

Acknowledgments: We thank Alireza Khasheei for technical support and Anne Wölffel-Gale for editorial assistance.

Conflicts of Interest: The authors declare no conflict of interest.

\section{References}

1. Afshin, A.; Afshin, A.; Forouzanfar, M.H.; Reitsma, M.B.; Sur, P.; Estep, K.; Lee, A.; Marczak, L.; Mokdad, A.H.; Moradi-Lakeh, M.; et al. Health effects of overweight and obesity in 195 countries over 25 years. N. Engl. J. Med. 2017, 377, 13-27.

2. Hall, J.E.; da Silva, A.A.; do Carmo, J.M.; Dubinion, J.; Hamza, S.; Munusamy, S.; Smith, G.; Stec, D.E. Obesity-induced hypertension: Role of sympathetic nervous system, leptin, and melanocortins. J. Biol. Chem. 2010, 285, 17271-17276. [CrossRef] [PubMed]

3. Tchkonia, T.; Thomou, T.; Zhu, Y.; Karagiannides, I.; Pothoulakis, C.; Jensen, M.D.; Kirkland, J.L. Mechanisms and metabolic implications of regional differences among fat depots. Cell Metab. 2013, 17, 644-656. [CrossRef] [PubMed] 
4. Malta, D.; Petersen, K.S.; Johnson, C.; Trieu, K.; Rae, S.; Jefferson, K.; Santos, J.A.; Wong, M.M.Y.; Raj, T.S.; Webster, J.; et al. High sodium intake increases blood pressure and risk of kidney disease. From the Science of Salt: A regularly updated systematic review of salt and health outcomes (August 2016 to March 2017). J. Clin. Hypertens. 2018, 20, 1654-1665. [CrossRef] [PubMed]

5. Mozaffarian, D.; Fahimi, S.; Singh, G.M.; Micha, R.; Khatibzadeh, S.; Engell, R.E.; Lim, S.; Danaei, G.; Ezzati, M.; Powles, J. Global sodium consumption and death from cardiovascular causes. N. Engl. J. Med. 2014, 371, 624-634. [CrossRef] [PubMed]

6. He, J.; Ogden, L.G.; Vupputuri, S.; Bazzano, L.A.; Loria, C.; Whelton, P.K. Dietary sodium intake and subsequent risk of cardiovascular disease in overweight adults. Jama 1999, 282, 2027-2034. [CrossRef]

7. Lerchl, K.; Lerchl, K.; Rakova, N.; Dahlmann, A.; Rauh, M.; Goller, U.; Basner, M.; Dinges, D.F.; Beck, L.; Agureev, A.; et al. Agreement between 24-hour salt ingestion and sodium excretion in a controlled environment. Hypertension 2015, 66, 850-857. [CrossRef]

8. Kopp, C.; Linz, P.; Wachsmuth, L.; Dahlmann, A.; Horbach, T.; Schofl, C.; Renz, W.; Santoro, D.; Niendorf, T.; Muller, D.N.; et al. ${ }^{23} \mathrm{Na}$ magnetic resonance imaging of tissue sodium. Hypertension 2012, 59, $167-172$. [CrossRef]

9. Kopp, C.; Linz, P.; Dahlmann, A.; Hammon, M.; Jantsch, J.; Muller, D.N.; Schmieder, R.E.; Cavallaro, A.; Eckardt, K.U.; Uder, M.; et al. ${ }^{23} \mathrm{Na}$ magnetic resonance imaging-determined tissue sodium in healthy subjects and hypertensive patients. Hypertension 2013, 61, 635-640. [CrossRef]

10. Dahlmann, A.; Dorfelt, K.; Eicher, F.; Linz, P.; Kopp, C.; Mossinger, I.; Horn, S.; Buschges-Seraphin, B.; Wabel, P.; Hammon, M.; et al. Magnetic resonance-determined sodium removal from tissue stores in hemodialysis patients. Kidney Int. 2015, 87, 434-441. [CrossRef]

11. Hammon, M.; Grossmann, S.; Linz, P.; Kopp, C.; Dahlmann, A.; Garlichs, C.; Janka, R.; Cavallaro, A.; Luft, F.C.; Uder, M.; et al. ${ }^{23} \mathrm{Na}$ magnetic resonance imaging of the lower leg of acute heart failure patients during diuretic treatment. PLoS ONE 2015, 10, e0141336. [CrossRef] [PubMed]

12. Hammon, M.; Grossmann, S.; Linz, P.; Kopp, C.; Dahlmann, A.; Garlichs, C.; Janka, R.; Cavallaro, A.; Luft, F.C.; Uder, M.; et al. 3 Tesla ${ }^{23} \mathrm{Na}$ magnetic resonance imaging during acute kidney injury. Acad. Radiol. 2017, 24, 1086-1093. [CrossRef] [PubMed]

13. Schneider, M.P.; Raff, U.; Kopp, C.; Scheppach, J.B.; Toncar, S.; Wanner, C.; Schlieper, G.; Saritas, T.; Floege, J.; Schmid, M.; et al. Skin sodium concentration correlates with left ventricular hypertrophy in CKD. J. Am. Soc. Nephrol. 2017, 28, 1867-1876. [CrossRef] [PubMed]

14. Kromeyer-Hauschild, K.; Wabitsch, M.; Kunze, D.; Geller, F.; Geiß, H.C.; Hesse, V.; von Hippel, A.; Jaeger, U.; Johnsen, D.; Korte, W.; et al. Perzentile für den Body-mass-Index für das Kindes- und Jugendalter unter Heranziehung verschiedener deutscher Stichproben. Mon. Kinderheilkd. 2001, 149, 807-818. [CrossRef]

15. Flynn, J.T.; Kaelber, D.C.; Baker-Smith, C.M.; Blowey, D.; Carroll, A.E.; Daniels, S.R.; de Ferranti, S.D.; Dionne, J.M.; Falkner, B.; Flinn, S.K.; et al. Clinical practice guideline for screening and management of high blood pressure in children and adolescents. Pediatrics 2017, 140. [CrossRef] [PubMed]

16. Neuhauser, H.K.; Thamm, M.; Ellert, U.; Hense, H.W.; Rosario, A.S. Blood pressure percentiles by age and height from nonoverweight children and adolescents in Germany. Pediatrics 2011, 127, e978-e988. [CrossRef]

17. Wang, P.; Deger, M.S.; Kang, H.; Ikizler, T.A.; Titze, J.; Gore, J.C. Sex differences in sodium deposition in human muscle and skin. Magn. Reason. Imaging 2017, 36, 93-97. [CrossRef]

18. Machnik, A.; Neuhofer, W.; Jantsch, J.; Dahlmann, A.; Tammela, T.; Machura, K.; Park, J.K.; Beck, F.X.; Muller, D.N.; Derer, W.; et al. Macrophages regulate salt-dependent volume and blood pressure by a vascular endothelial growth factor-C-dependent buffering mechanism. Nat. Med. 2009, 15, 545-552. [CrossRef]

19. Kopp, C.; Linz, P.; Maier, C.; Wabel, P.; Hammon, M.; Nagel, A.M.; Rosenhauer, D.; Horn, S.; Uder, M.; Luft, F.C.; et al. Elevated tissue sodium deposition in patients with type 2 diabetes on hemodialysis detected by ${ }^{23} \mathrm{Na}$ magnetic resonance imaging. Kidney Int. 2018, 93, 1191-1197. [CrossRef]

20. GenSaltGroup. GenSalt: Rationale, design, methods and baseline characteristics of study participants. J. Hum. Hypertens. 2007, 21, 639-646. [CrossRef]

21. Kopp, C.; Beyer, C.; Linz, P.; Dahlmann, A.; Hammon, M.; Jantsch, J.; Neubert, P.; Rosenhauer, D.; Muller, D.N.; Cavallaro, A.; et al. $\mathrm{Na}^{+}$deposition in the fibrotic skin of systemic sclerosis patients detected by ${ }^{23} \mathrm{Na}$-magnetic resonance imaging. Rheumatology 2017, 56, 674. [CrossRef] [PubMed] 
22. Crescenzi, R.; Marton, A.; Donahue, P.M.C.; Mahany, H.B.; Lants, S.K.; Wang, P.; Beckman, J.A.; Donahue, M.J.; Titze, J. Tissue sodium content is elevated in the skin and subcutaneous adipose tissue in women with lipedema. Obesity 2017, 26, 310-317. [CrossRef] [PubMed]

23. WHO. WHO Guidelines Approved by the Guidelines Review Committee. In Guideline: Sodium Intake for Adults and Children; World Health Organization: Geneva, Switzerland, 2012.

24. Kurtz, T.W.; DiCarlo, S.E.; Pravenec, M.; Schmidlin, O.; Tanaka, M.; Morris, R.C., Jr. An alternative hypothesis to the widely held view that renal excretion of sodium accounts for resistance to salt-induced hypertension. Kidney Int. 2016, 90, 965-973. [CrossRef] [PubMed]

25. Rakova, N.; Rakova, N.; Juttner, K.; Dahlmann, A.; Schroder, A.; Linz, P.; Kopp, C.; Rauh, M.; Goller, U.; Beck, L.; et al. Long-term space flight simulation reveals infradian rhythmicity in human $\mathrm{Na}(+)$ balance. Cell Metab. 2013, 17, 125-131. [CrossRef] [PubMed]

26. Wilck, N.; Matus, M.G.; Kearney, S.M.; Olesen, S.W.; Forslund, K.; Bartolomaeus, H.; Haase, S.; Mahler, A.; Balogh, A.; Marko, L.; et al. Salt-responsive gut commensal modulates TH17 axis and disease. Nature 2017, 551, 585-589. [CrossRef] [PubMed]

27. Freitas, S.R.S. Molecular genetics of salt-sensitivity and hypertension: role of renal epithelial sodium channel genes. Am. J. Hypertens. 2017, 31, 172-174. [CrossRef]

28. Yatabe, M.S.; Yatabe, J.; Yoneda, M.; Watanabe, T.; Otsuki, M.; Felder, R.A.; Jose, P.A.; Sanada, H. Salt sensitivity is associated with insulin resistance, sympathetic overactivity, and decreased suppression of circulating renin activity in lean patients with essential hypertension. Am. J. Clin. Nutr. 2010, 92, 77-82. [CrossRef]

29. Elijovich, F.; Weinberger, M.H.; Anderson, C.A.; Appel, L.J.; Bursztyn, M.; Cook, N.R.; Dart, R.A.; Newton-Cheh, C.H.; Sacks, F.M.; Laffer, C.L.; et al. Salt sensitivity of blood pressure: A scientific statement from the American Heart Association. Hypertension 2016, 68, e7-e46. [CrossRef]

30. Oberleithner, H. Two barriers for sodium in vascular endothelium? Ann. Med. 2012, 44, S143-S148. [CrossRef]

31. Garofalo, C.; Borrelli, S.; Provenzano, M.; De Stefano, T.; Vita, C.; Chiodini, P.; Minutolo, R.; De Nicola, L.; Conte, G. Dietary salt restriction in chronic kidney disease: A meta-analysis of randomized clinical trials. Nutrients 2018, 10, 732. [CrossRef]

32. Brands, M.W.; Manhiani, M.M. Sodium-retaining effect of insulin in diabetes. Am. J. Physiol. Regul. Integr. Comp. Physiol. 2012, 303, R1101-R1109. [CrossRef] [PubMed]

33. Zhou, M.S.; Liu, C.; Tian, R.; Nishiyama, A.; Raij, L. Skeletal muscle insulin resistance in salt-sensitive hypertension: Role of angiotensin II activation of NFkappaB. Cardiovasc. Diabetol. 2015, 14, 45. [CrossRef] [PubMed]

34. Deger, S.M.; Wang, P.; Fissell, R.; Ellis, C.D.; Booker, C.; Sha, F.; Morse, J.L.; Stewart, T.G.; Gore, J.C.; Siew, E.D.; et al. Tissue sodium accumulation and peripheral insulin sensitivity in maintenance hemodialysis patients. J. Cachexia Sarcopenia Muscle 2017, 8, 500-507. [CrossRef] [PubMed]

35. Han, S.Y.; Kim, N.H.; Kim, D.H.; Han, K.; Kim, S.M. Relationship between urinary sodium-creatinine ratios and insulin resistance in Korean children and adolescents with obesity. J. Pediatr. Endocrinol. Metab. 2018, 31, 375-383. [CrossRef]

(C) 2019 by the authors. Licensee MDPI, Basel, Switzerland. This article is an open access article distributed under the terms and conditions of the Creative Commons Attribution (CC BY) license (http://creativecommons.org/licenses/by/4.0/). 